\title{
Metachronous Nodal and Nasal Rosai-Dorfman Disease presenting with Chronic Renal Failure
}

\author{
Shubha P Bhat, HL Kishan Prasad, B Satheesh Kumar Bhandary, Shashidhar Baikunje, Vadisha Bhat
}

\section{ABSTRACT}

Rosai-Dorfman disease (RDD) is an uncommon non-neoplastic lymphoproliferative disorder. It usually manifests as bilateral, painless, massive cervical lymph node enlargement in children and young adults, hence the name sinus histiocytosis with massive lymphadenopathy. Extranodal involvement is observed in 25 to $40 \%$ of cases. Involvement of nasal cavity is rare and those presenting with renal failure are exceptional. We report a rare case of 16 -year-old boy who was diagnosed as a case of RDD of cervical lymph node before 6 years, now presenting with nodular lesions in the nasal cavity and features of renal failure. The nasal lesion was confirmed to be RDD histologically.

Keywords: Rosai-Dorfman disease, Nasal cavity, Renal failure.

How to cite this article: Bhat SP, Prasad HLK, Bhandary BSK, Baikunje S, Bhat V. Metachronous Nodal and Nasal Rosai Dorfman Disease presenting with Chronic Renal Failure. Clin Rhinol An Int J 2013;6(3):139-143.

\section{Source of support: Nil}

Conflict of interest: None declared

\section{INTRODUCTION}

Rosai-Dorfman disease (RDD) is a rare disorder first described in 1969. ${ }^{1}$ However, the first description of this clinical entity was given by Lampert and lennert in $1961 .^{2}$ RDD generally occur in children or young adults with massive cervical lymphadenopathy, fever, leukocytosis, increased erythrocyte sedimentation rate and hypergammaglobulinemia. Other lymph node groups may be affected. In about 25 to $40 \%$ of cases extranodal sites may be affected like eyelids, orbit, respiratory tract, salivary glands, skin, bone, testis, lung, kidney, central nervous system, thyroid and gastrointestinal tract. ${ }^{3}$ Renal involvement is rarely described and is generally asymptomatic or may present with renal failure. ${ }^{4}$ Diagnosis of the disease is established by histological examination of biopsy specimen. Treatment is not well defined and includes surgery, antibiotics, radiotherapy, chemotherapy, and steroids, sometimes in combination. But none of these have provided consistent results. The clinical course of the disease is variable with spontaneous remissions and subsequent relapses at times. ${ }^{5}$ Multifocal and synchronous nodal and nasal RDD have been reported. Here we report a case of metachronous nodal and nasal RDD of long duration presenting with renal failure.

\section{CASE REPORT}

A 16-year-old boy presented with history of intermittent bleeding from the nose since 4 months, generalized weakness and facial and pedal edema since 2 weeks. He gave history of undergoing excision of right sided cervical lymph node before 6 years, and the histopathology report was sinus histiocytosis with massive lymphadenopathy (RosaiDorfman disease). General examination revealed pallor, facial and pedal edema. Blood pressure was 170/80 mm Hg. On anterior rhinoscopy, there was a nodular mass involving the anterior part of nasal septum (Fig. 1). On diagnostic endoscopy and similar nodules were found on both middle turbinates (Fig. 2) and floor of left nasal cavity (Fig. 3) and

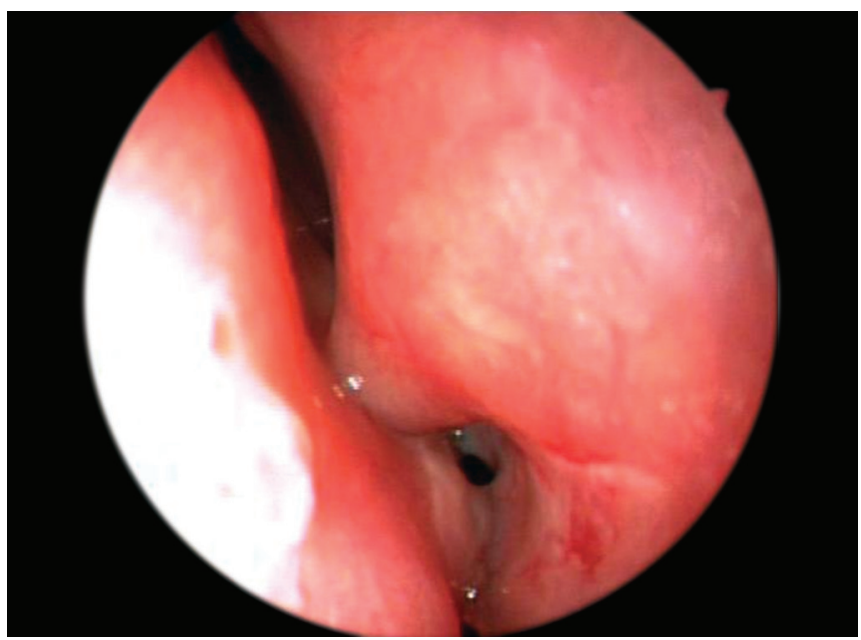

Fig. 1: Clinical photograph showing nodular lesion over nasal septum

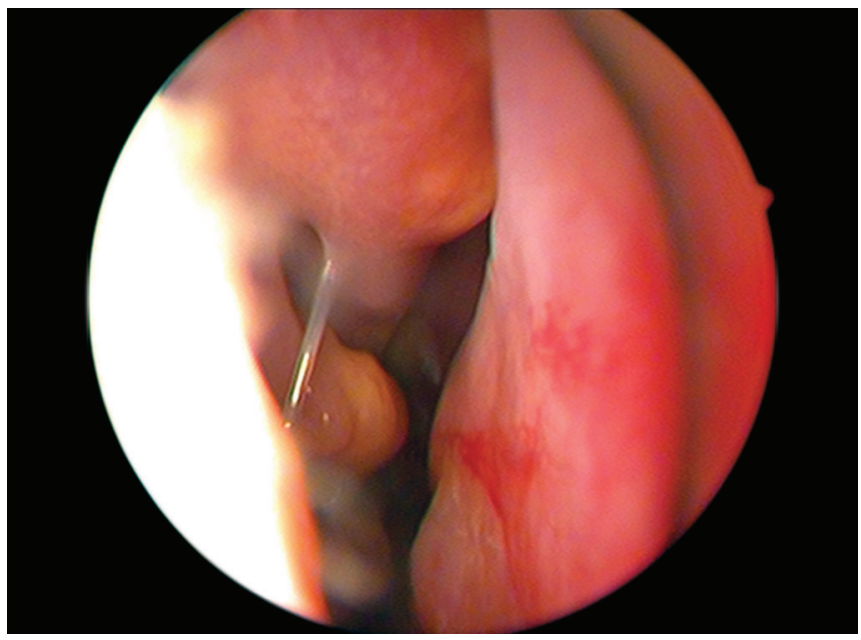

Fig. 2: Clinical photograph showing lesion over right middle turbinate 
in the nasopharynx (Fig. 4). The nodule was friable and bleeds easily on touch. CT scan of the paranasal sinus (plain) showed soft tissue mass lesion involving the anterior nasal septum (Fig. 5), right middle turbinate and right anterior ethmoid sinus (Fig. 6), left middle turbinate, floor of the left nasal cavity (Fig. 7) and nasopharynx (Fig. 8). Sclerosis of nasal bones was noted. His hemoglobin level was 4.3 $\mathrm{g} / \mathrm{dL}$, Total leukocyte count was $13400 / \mathrm{cmm}$. Blood urea was $75 \mathrm{mg} / \mathrm{dl}$ and serum creatinine was $9.1 \mathrm{mg} / \mathrm{dl}$. Serum electrolytes were within normal limits. Urine analysis revealed proteinuria. Ultrasound abdomen showed bilateral grade II Medical renal disease, bilateral small kidneys with increased echogenesity and loss of corticomedullary differentiation. His hemoglobin level was improved to 11 $\mathrm{g} / \mathrm{dL}$ after transfusing 4 units of packed cells. Biopsy was taken from the nasal and nasopharyngeal lesions and the histopathology showed normal mucosa with submucosa showing histiocytes with abundant cytoplasm and lymphoid cells (Fig. 9). The histiocytes were showing 'emperipolesis'

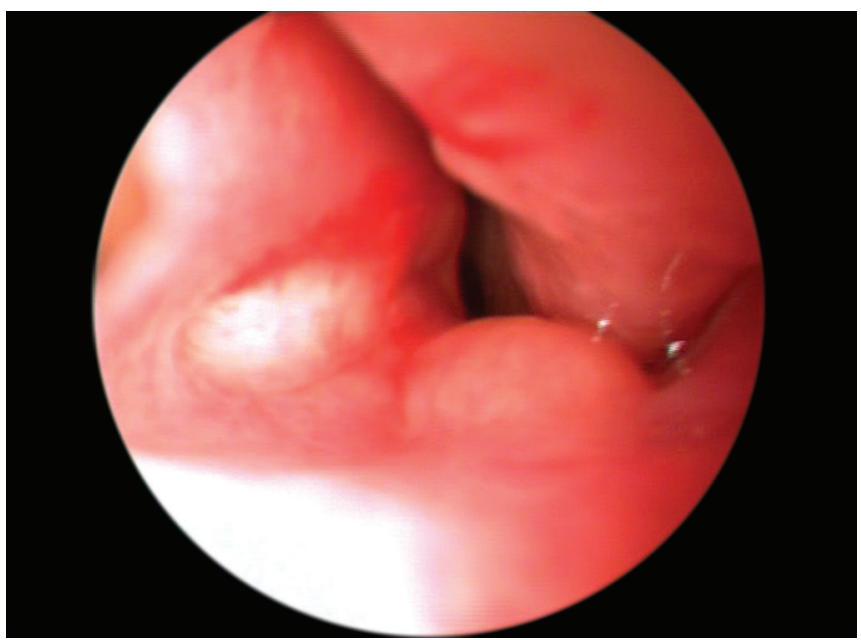

Fig. 3: Clinical photograph showing lesion over floor of left nasal cavity

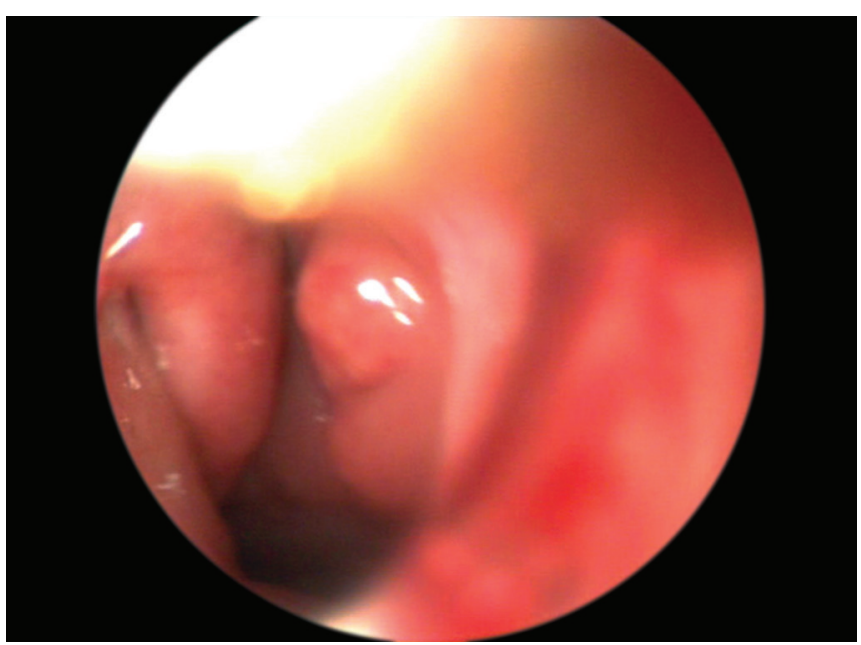

Fig. 4: Clinical photograph showing lesion in the nasopharynx (lymphohistiophagocytosis) (Fig. 10). There were plasma cells showing Russel bodies (Fig. 11). Histological features were suggestive of extranodal RDD. However to rule out

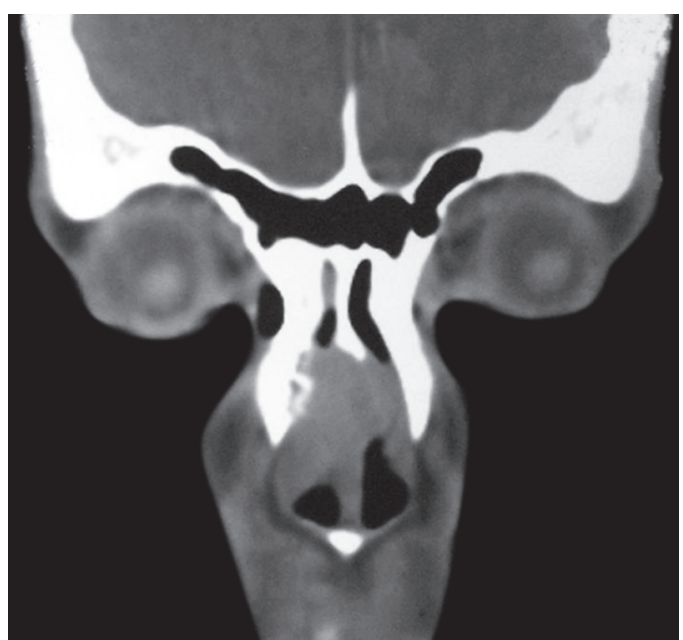

Fig. 5: CT scan paranasal sinus-coronal image, showing soft tissue mass lesion over nasal septum

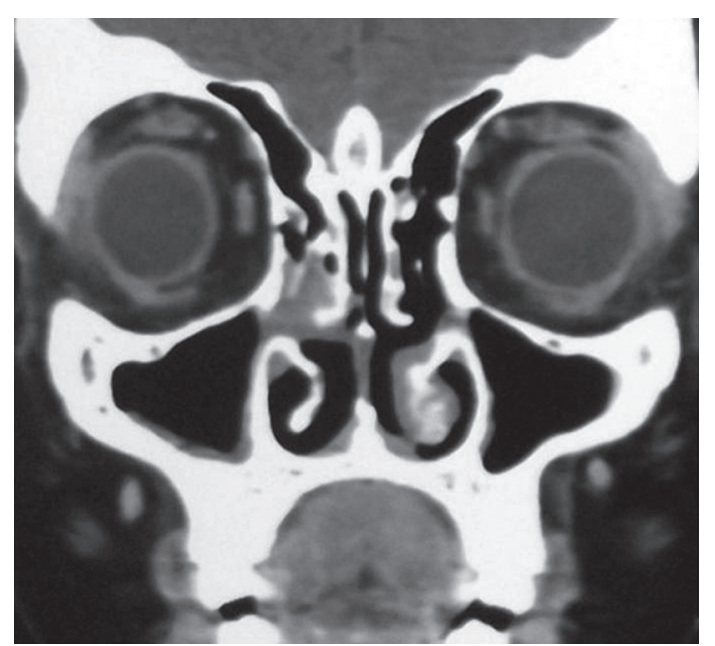

Fig. 6: CT scan paranasal sinus-coronal image, showing soft tissue mass lesion over right middle turbinate and right anterior ethmoid sinus

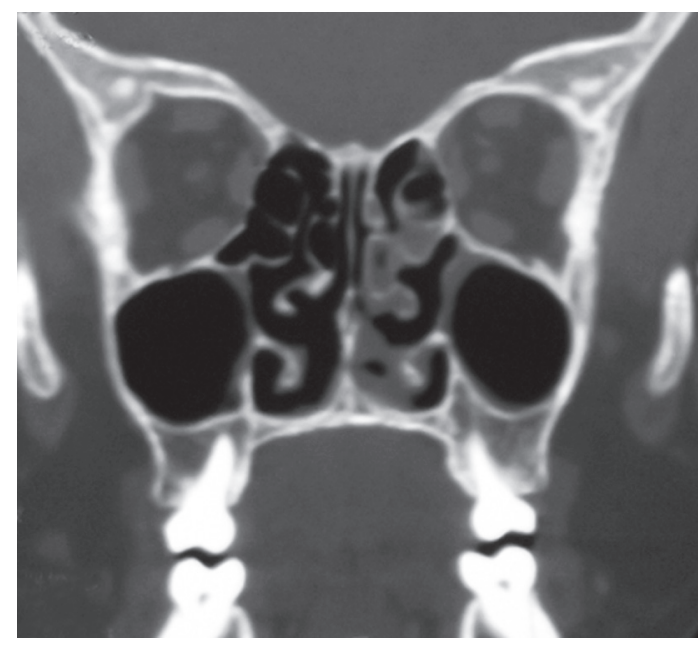

Fig. 7: CT scan paranasal sinus-coronal image, showing soft tissue mass lesion over floor of left nasal cavity 


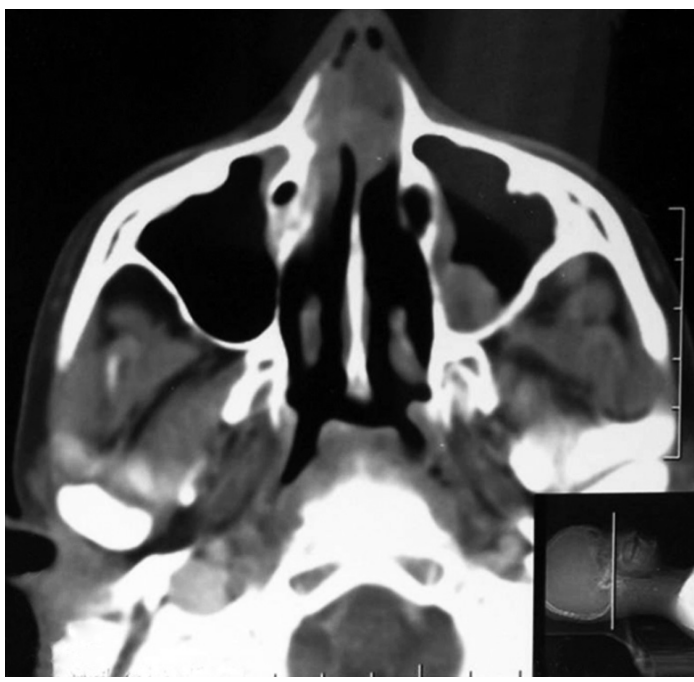

Fig. 8: CT scan paranasal sinus (axial image), showing soft tissue mass lesion in the anterior nasal cavity and nasopharynx

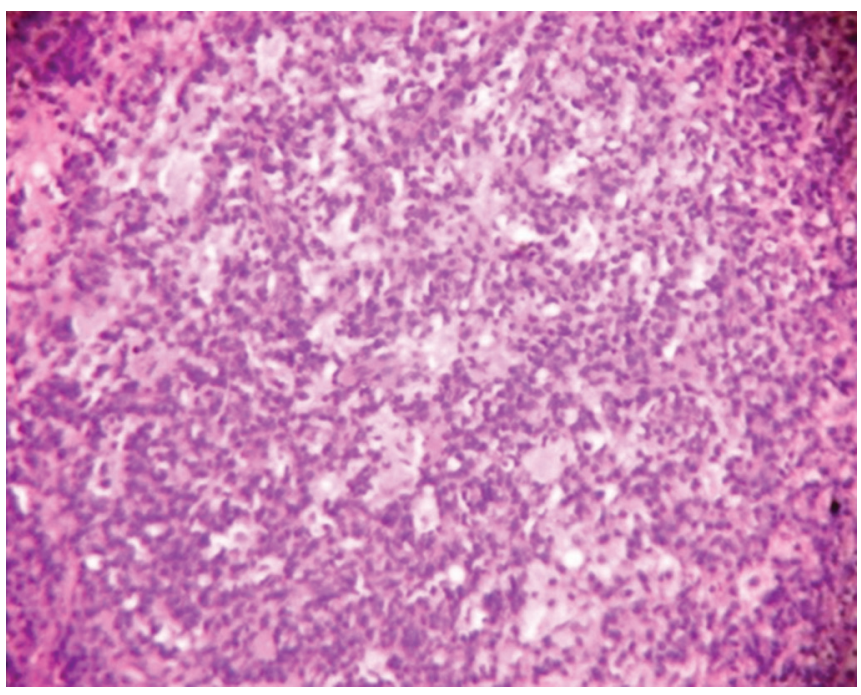

Fig. 9: $\mathrm{H}$ and $\mathrm{E}$ staining (low power) showing histiocytes with abundant cytoplasm and lymphoid cells in the submucosa

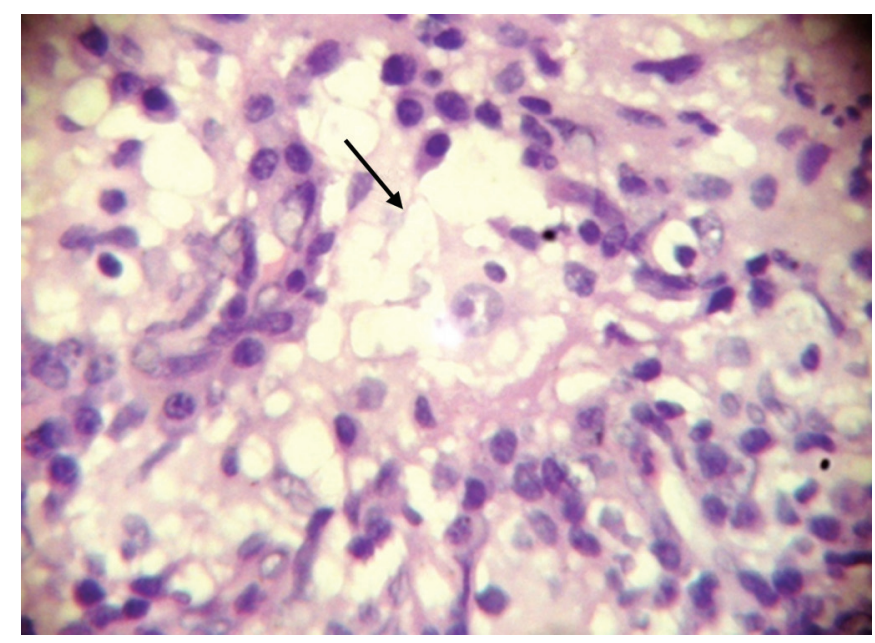

Fig. 10: $\mathrm{H}$ and $\mathrm{E}$ staining (high power) — histiocytes showing emperipolesis (Lymphohistiophagocytosis)

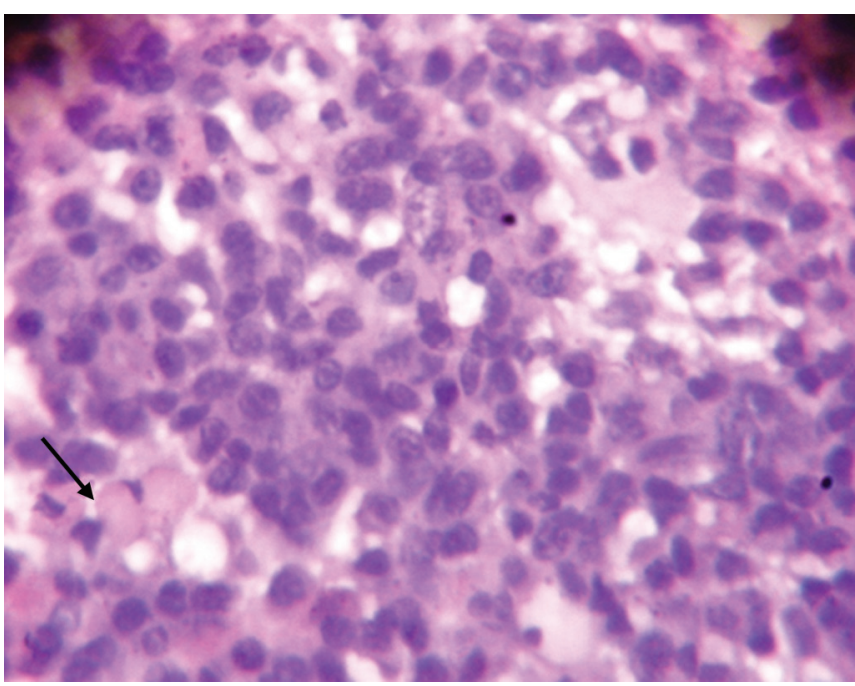

Fig. 11: $\mathrm{H}$ and $\mathrm{E}$ staining (high power)—plasma cells showing Russel bodies

wageners granulomatosis, C-ANCA and P-ANCA were advised both of which were negative. Not to leave any chance, lymphoma panel immunohistochemistry was performed. CD 1a (for Langerhans cell histiocytosis), CD 3 (for T cell), CD 19, 20 (for B cell, Non Hodgkins lymphoma) and CD 15, 30 were Negative (Hodgkins Lymphoma). A final diagnosis of extranodal RDD was made. Intravenous Methylprednisolone $500 \mathrm{mg}$ was administered for 3 days followed by oral prednisolone $50 \mathrm{mg}$ once daily tapered over 2 weeks. Hemodialysis is being done through an AV fistula, two times a week to maintain the renal parameters. He is under regular follow-up since 2 years with antihypertensive medication and hemodialysis. As there is no improvement in renal function, he is being worked up for renal transplant. Meanwhile, the nasal lesions are static without causing any further symptoms.

\section{DISCUSSION}

Rosai-Dorfman disease (RDD) is a rare disorder first described in 1969 that occurs most often in children or young adults. ${ }^{1}$ Males are more commonly affected than females. ${ }^{3}$ The patient described here is a 16 -year-old male. Lymphadenopathy of the neck is the most common site. Extranodal manifestations of this disease are uncommon. The most common extranodal sites are skin, upper respiratory tract, bone and sinuses, rarely kidneys and urogenital system. ${ }^{4}$ The concomitant involvement of one or more sites in the same individual is observed in up to $44.7 \%$ of extranodal cases. ${ }^{3}$ Nasal cavity involvement is rare, and mimics tuberculosis or lymphoma. They are usually self limiting, only extensive lesions requiring surgical excision. $^{5}$ 
Approximately $4 \%$ of cases of RDD are associated with kidney involvement, where it usually presents as involvement of the kidney by systemic disease or at the least has an association with nodal disease. ${ }^{6}$ De Jong et al observed that RDD of kidney might be related to IgG4 related disease, as they have found high IgG4 levels in their patient with RDD of cervical lymph node, also having pulmonary and renal lesions. ${ }^{7}$ However, in very rare cases similar to that of our patient, renal failure is a sole manifestation of the renal involvement by the disease.

Etiology of RDD is not established yet. However studies have shown that there is a relation between RDD and some viral infections mainly human herpes virus- 6 and Epstein-Barr virus. ${ }^{6}$ Varicell- Zoster, Cytomegalovirus, Brucella and Klebsiella infections are also implicated in the etiology of RDD. ${ }^{8}$ Associated symptoms and signs could be constitutional; such as fever and weight loss, or organ associated when extranodal involvement is present. ${ }^{9}$ Our patient was a known case of RDD of cervical lymph node diagnosed 6 years back, now presented with epistaxis and features of renal failure. Hematological alterations include anemia, leukocytosis, neutrophilia, increased ESR, and hypergammaglobulinemia. ${ }^{10}$ Imaging helps in assessing the disease extension. If there is cervical lymph node enlargement, fine needle aspiration biopsy or lymph node biopsies may be useful for the diagnosis. ${ }^{9}$ Our patient had anemia, leukocytosis, relative neutrophilia, thrombocytopenia, high ESR, elevated urea and creatinine levels, and proteinuria. Ultrasound abdomen showed bilateral small kidneys with Grade II Medical renal disease with increased echogenesity and loss of corticomedullary differentiation. For evaluation of nasal mass, we could do only noncontrast CT scan of paranasal sinus, as contrast could not be administered because of renal dysfunction.

The differential diagnosis of RDD includes malignant lymphoreticular neoplasias such as Hodgkin's disease and monocytic leukemia, Langerhans cell histiocytosis, rhinoscleroma, tuberculosis, juvenile xanthogranuloma, dermatofibromas and eosinophilic granuloma. ${ }^{3}$ The diagnosis of extranodal RDD may be a challenge and is based on clinical and histological examination. Histology shows typical features, such as diffuse lymphoplasmacytic infiltration, Russel bodies, foamy histiocytes and histiocytes with phagocytosed lymphocytes within the cytoplasm (emperipolesis). ${ }^{9}$ Diagnosis of RDD in renal disease is difficult histologically- diagnosis by high index of suspicion in known case of RDD, after exclusion of lymphoma. ${ }^{11}$

Treatment is necessary only when the disorder becomes life-threatening or organ threatening. There is no specific treatment for RDD. The treatment modes include corticosteroids, chemotherapy with a combination of vinca alkaloids and alkylating agents, low dose interferon, radiation therapy and surgical treatment. Surgical options are reserved for compressive symptoms, like airway obstruction, neurologic or ocular compressions. ${ }^{3}$ The natural course of the disease is generally favorable resulting in complete resolution in $25 \%$ of the cases. ${ }^{3}$ Involvement of abdominal organs is associated with progressive nonremitting disease. ${ }^{11}$ In patients with renal involvement, $40 \%$ die with the disease, or because of the disease. ${ }^{6}$ Our patient was a case of metachronous nodal and nasal RDD, presented with chronic renal failure. After corticosteroid therapy, his nasal lesions became static, even though they did not disappear completely. As he did not have further symptoms pertaining to the nose, surgery was not undertaken. He is on hemodialysis through an $\mathrm{AV}$ fistula since 2 years to maintain the renal parameters. He is tolerating the treatment well without any signs of progression of the disease.

\section{CONCLUSION}

RDD is a rare idiopathic histiocytosis which typically involves lymph nodes. Extranodal sites can be involved synchronously or metachronously. Renal failure can be a presenting feature. Clinicians have to be aware of this disease which poses a diagnostic and therapeutic challenge. Biopsy should be done and subjected to histopathological examination for definite diagnosis.

\section{ACKNOWLEDGMENTS}

We are thankful to Dr Jayaprakash Shetty, Professor and Head of Pathology, Dr JH Makannavar, Professor of Pathology, Dr Srikrishna U, Professor of Radiology, KS Hegde Medical Academy for their help.

\section{REFERENCES}

1. Rosai J, Dorfman RF. Sinus histiocytosis with massive lymphadenopathy. Anewly recognized benign clinicopathological entity. Arch Pathol 1969, 87(1):63-70.

2. Lampert F, Lennert K. Sinus histiocytosis with massive lymphadenopathy: fifteen new cases. Cancer 1976;37:783-789.

3. Bist SS, Bisht M, Varshney S, Pathak VP. Rosai Dorfman Syndrome with Extranodal manifestation. Assoc Physicians India 2007;55:445-447.

4. Krishnan A, Nasar A, Nieh PT. Rosai-Dorfman disease presenting as extranodal renal mass. Urology 2005;66:1319.

5. Ku PK, Tong MC, Leung CY, Pak MW, van Hasselt CA. Nasal manifestation of extranodal Rosai-Dorfman disease - diagnosis and management. J Laryngol Otol 1999; 113(3):275-280.

6. Harik L, Nassar A. Extranodal Rosai-Dorfman disease of the kidney and Coexistent Poorly Differentiated Prostatic Adenocarcinoma. Arch Pathol Lab Med 2006;130:1223-1226.

7. De Jong WK, Kluin PM, Groen HJM. Overlapping immunoglobulin G4-related disease and Rosai-Dorfman disease mimicking lung cancer. Europian Respiratory Review; 21(126):365-367. 
8. Henter JI, Tondini C, Pritchard J. Histiocyte disorders. Crit Rev Oncol Hematol 2004, 50(2):157-174.

9. Pinto DCG, Vidigal TA, Castro B, Santos BH, Sousa NJA. Rosai- Dorfman disease in the differential diagnosis of cervical lymphadenopathy. Bras J Otorhinolaryngol 2008;74(4): 632-635.

10. Nastouli E, Carrol E, Malone M, Riordan A, Lyall H. Fatal histiocytic proliferative disorders in paediatric HIV infection with cytomegalovirus end-organ disease. British J Haematol 2009; 146:580-582.

11. Lai FM, To KF, Szeto CC, et al. Acute renal failure in a patient with Rosai-Dorfman disease. Am J Kidney Dis 1999;34:e12.

\section{ABOUT THE AUTHORS}

\section{Shubha P Bhat}

Assistant Professor, Department of Pathology, KS Hegde Medical Academy, Mangalore, Karnataka, India

\section{HL Kishan Prasad}

Associate Professor, Department of Pathology, KS Hegde Medical Academy, Mangalore, Karnataka, India

\section{B Satheesh Kumar Bhandary}

Professor, Department of ENT, KS Hegde Medical Academy Mangalore, Karnataka, India

\section{Shashidhar Baikunje}

Professor, Department of Nephrology, KS Hegde Medical Academy Mangalore, Karnataka, India

\section{Vadisha Bhat (Corresponding Author)}

Associate Professor, Department of ENT, KS Hegde Medical Academy, Mangalore, Karnataka, India, Phone: 9480174828 , e-mail: bvadish@yahoo.co.in 